\title{
Resistência de espécies arbóreas submetidas a extremos climáticos de geada em diferentes sistemas agroflorestais
}

\author{
Resistance of arboreal species submitted to extreme frost in different agroforestry systems
}

\author{
Velci Queiróz de SouzaI Braulio Otomar Caron'II Denise Schmidt"II Alexandre BehlingII \\ Rogério BambergII Andre Luis Vian"I
}

\section{RESUMO}

O presente trabalho teve como objetivo avaliar a resposta das espécies arbóreas Schizolobium parahyba (Vell.) Blake (guapuruvu), Mimosa scabrella Benth. (bracatinga), Peltophorum dubium (Spr.) Taubert (canafístula), Parapiptadenia rigida (Benth.) Brenan (angico-vermelho) e o híbrido Eucalyptus urophylla S.T. Blake $x$ Eucalyptus grandis Hill ex Maiden (eucalipto) em consórcio com a cana-de-açúcar (Saccharum spp.) em dois arranjos de sistemas agroflorestais (faixa $-3 \times 3 m+12 m$ e linha $-6 \times 1,5 m$ ) submetidos a extremos climáticos de geada, na região Noroeste do Rio Grande do Sul. Os danos (resistência á geada) foram avaliados segundo o sistema de notas utilizado por HIGA et al. (2000) no qual atribuiu-se uma nota de 0 a 10 conforme a intensidade do dano na planta. Para os graus de resistência à geada, adaptouse metodologia utilizada por CARVALHO (1981), a qual também é em função da intensidade do dano na planta. Diante da condição de geada estudada, observa-se que os diferentes arranjos de sistemas agroflorestais afetam a resistência da espécie guapuruvu, sendo sensível no sistema agroflorestal faixa e moderadamente tolerante no sistema linha. Em ambos os sistemas, as espécies angico-vermelho, bracatinga e eucalipto mostram-se resistentes, enquanto que a canafístula demonstra ser tolerante.

Palavras-chave: tolerância ao frio, espécies florestais, espaçamento florestal.

\section{ABSTRACT}

The present research had the aim to evaluate the answers of the arboreal species Schizolobium parahyba (Vell.)
Blake (guapuruvu), Mimosa scabrella Benth. (bracatinga), Peltophorum dubium (Spr.) Taubert (canafístula), Parapiptadenia rigida (Benth.) Brenan (angico-vermelho) and the hybrid Eucalyptus urophylla S.T. Blake x Eucalyptus grandis Hill ex Maiden (eucalipto) in consortium with sugar cane (Saccharum spp.) in two agroforestry arrangement systems (strip - 3x3m $+12 m$ and line $-6 \times 1,5 m$ ) submitted to climatic extreme frost conditions, in the Northwest of Rio Grande do Sul. The damages (resistance to frost) were appraised according to the system of notes used by HIGA et al. (2000) in which a note from 0 to 10 was attributed according to the intensity of the damage to the plant. For the resistance degrees to frost, it was adapted the methodology used by CARVALHO (1981), which is also in function of the intensity of the damage to the plant. Upon the frost condition studied, it was observed that the results demonstrated that different of agroforest system arrangements damaged the resistance of the guapuruvu specie, being sensitive in the agroforest system strip and moderatelly tolerant in the system line. In both systems, the species angicovermelho, bracatinga e eucalipto showed resistance, while the canafístula demonstrated to be tolerant.

Key words: cold tolerance, forest species, forest spacing.

\section{INTRODUÇÃo}

A ocorrência de geada no Brasil é um fenômeno frequente nas latitudes acima do paralelo $19^{\circ} \mathrm{S}$, atingindo os estados de São Paulo, Mato Grosso do Sul, Minas Gerais, Paraná, Santa Catarina e Rio Grande do Sul (PEREIRA et al., 2001). De acordo com a

IDepartamento de Melhoramento Genético de Plantas, Centro de Educação Superior Norte do Rio Grande do Sul (CESNORS), Universidade Federal de Santa Maria (UFSM), 98400-000, Frederico Westphalen, RS, Brasil. E-mail: velciq@smail.ufsm.br. Autor para correspondência.

IIDepartamento de Agroclimatologia, CESNORS, UFSM, Frederico Westphalen, RS, Brasil

IIIDepartamento de Produção Vegetal, CESNORS, UFSM, Frederico Westphalen, RS, Brasil 
época de incidência dos frios danosos para a vegetação, as geadas podem ser diferenciadas em outonais, invernais e primaveris. No estado do Rio Grande do Sul, é maior a probabilidade de ocorrência de geadas tardias (primaveris) do que as precoces (outonais), sendo que os maiores valores de probabilidade de ocorrência de geada são no segundo decêndio de julho.

O espaçamento entre as plantas é um dos fatores que pode estar relacionado com os danos provocados por geada. Isso em razão da radiação solar interceptada através do dossel formado pela copa das árvores. Na linha de plantio, nos espaçamentos menores, ou seja, com maior densidade de plantas, ocorre formação de dossel precocemente quando comparado com os espaçamentos maiores. O dossel diminui as perdas radiativas durante a noite como demonstrado no trabalho conduzido por PILAU et al. (2007). Quando se tem um conjunto de diferentes espécies de plantas, como é o caso dos sistemas agroflorestais, é de se esperar diferentes formações de dosséis e consequentemente disparidade de intensidade de danos provocados por geada nas diferentes essências.

Os sistemas agroflorestais (SAF's) combinam a produção de espécies lenhosas em associações deliberadas com cultivos agrícolas e animais em uma mesma área, de forma simultânea ou temporal. A diversificação de culturas pode garantir melhor aproveitamento de nutrientes e maior renda ao pequeno produtor (OSPINA-ANTE, 2006). Com introdução de árvores, ocorre diminuição dos ventos, atenuação dos extremos térmicos (redução das máximas e aumento das mínimas), redução da radiação fotossinteticamente ativa, radiação global incidente e radiação líquida durante o dia e redução das perdas radiativas durante a noite, minimizando danos por geadas (CARAMORI et al., 2004).

O objetivo do presente trabalho foi avaliar a resposta das espécies arbóreas Schizolobium parahyba (Vell.) Blake (guapuruvu), Mimosa scabrella Benth. (bracatinga), Peltophorum dubium (Spr.) Taubert (canafístula), Parapiptadenia rigida (Benth.) Brenan (angico-vermelho) e do híbrido Eucalyptus urophylla S.T. Blake x Eucalyptus grandis Hill ex Maiden (eucalipto) em consórcio com a cana-de-açúcar (Saccharum spp.) em diferentes arranjos de sistema agroflorestal submetidas a extremos climáticos de geada, na região Noroeste do Rio Grande do Sul.

\section{MATERIAL E MÉTODOS}

O trabalho foi desenvolvido no município de Frederico Westphalen, RS, numa área localizada sob coordenadas geográficas $27^{\circ} 22^{\prime} \mathrm{S}, 53^{\circ} 25^{\prime} \mathrm{W}$ a $480 \mathrm{~m}$ de altitude. Segundo a classificação climática de Köppen, o clima da região é Cfa. Frederico Westphalen está distante de Iraí aproximadamente $30 \mathrm{~km}$, sendo o município tomado como referência para os dados de classificação climática. Conforme proposta de MALUF (2000), Iraí apresenta clima de tipo subtemperado subúmido, sendo a temperatura média anual de $18,8^{\circ} \mathrm{C}$ e temperatura média do mês mais frio de $13,3^{\circ} \mathrm{C}$.

Foi utilizado delineamento experimental de blocos completos casualizados para lograr homogeneidade das características estranhas dentro do bloco e deixar a heterogeneidade entre blocos, já que este se caracterizou pela combinação de todas as espécies arbóreas nos diferentes sistemas agroflorestais, sendo conduzido em três repetições. No planejamento dos tratamentos estudados, utilizou-se um fatorial de 2x5, ou seja, dois sistemas agroflorestais (faixa e linha) e cinco espécies florestais Schizolobium parahyba, Mimosa scabrella, Peltophorum dubium, Parapiptadenia rigida e Eucalyptus urophylla $\mathbf{x}$ Eucalyptus grandis). Em cada bloco, foram contempladas dez unidades experimentais nas quais foram distribuídas ao acaso a combinação sistema agroflorestal mais espécie arbórea. Em cada unidade experimental, as espécies florestais somam 15 plantas, sendo três centrais avaliadas individualmente.

No sistema faixa (SF), as espécies florestais estão distribuídas em faixas separadas por $12 \mathrm{~m}$, cada qual composta por três linhas, nas quais as plantas são espaçadas em 3x3m. A cana-de-açúcar (Saccharum spp.) está distribuída em seis linhas (entre as faixas no espaço de $12 \mathrm{~m}$ ) e duas linhas na faixa (entre as linhas de árvores). No sistema linha (SL), as espécies florestais estão distribuídas em $6 \times 1,5 \mathrm{~m}$, ou seja, $6 \mathrm{~m}$ entre linha e 1,5m entre planta na linha, sendo a canade-açúcar distribuída em três linhas. Em ambos os sistemas, a cana-de-açúcar está distribuída num espaçamento de $1,20 \mathrm{~m}$ e as linhas de árvores estão orientadas no sentido leste-oeste.

Os danos (resistência à geada) foram avaliados segundo o sistema de notas utilizado por HIGA et al. (2000). Nesse sistema, atribuiu-se uma nota de 0 a 10 para cada planta. Para atribuição dos graus de resistência à geada, adaptou-se metodologia utilizada por CARVALHO (1981). A ocorrência de geada foi observada nos dias 16 e 17 de junho de 2008 (oito meses após a instalação do experimento), no final da estação de outono, na qual foi realizada avaliação da altura das árvores (altura antes da geada - HA) e do diâmetro da copa. Após 45 dias da ocorrência da primeira geada, avaliaram-se os danos causados à parte aérea do vegetal e altura das plantas (altura depois da ocorrência da geada - HD) que sofreram danos. Três 
meses após a ocorrência da geada, foram avaliados o número de brotos e a porcentagem de sobrevivência das plantas.

A altura e o diâmetro de copa das árvores foi medida com auxílio de régua graduada em $\mathrm{cm}$. Para o diâmetro da copa, foram realizadas duas mensurações com auxílio de balizas (identificando os extremos da largura da copa), uma no sentido norte-sul e outra no leste-oeste. As notas dos danos foliares foram atribuídas visualmente e as do caule, através do cálculo de porcentagem com base nos dados das alturas HA e HD através do emprego da equação: \% de dano no caule $=(100-(H D x 100 / H A)$.

Os valores de temperatura foram obtidos da Estação Climatológica do INMET (Instituto Nacional de Meteorologia) vinculada ao Laboratório de Agroclimatologia do Departamento de Agronomia do CESNORS (Centro de Educação Superior Norte do Rio Grande do Sul). A estação situa-se cerca de $1.500 \mathrm{~m}$ do experimento, sob coordenadas $27,3956^{\circ} \mathrm{S}$ e $53,4294^{\circ} \mathrm{W}$.

Os dados obtidos a campo foram submetidos à análise estatística através do software SAS Learning Edition 8.0 (2003), em que se realizaram as análises de variância, teste F e teste de Tukey a 5\% de probabilidade. Foram testadas as pressuposições da análise de variância (normalidade e homogeneidade) e identificou-se qual o fator de correção que melhor as atendeu. Assim, as notas dos danos de geada foram transformadas em $\mathrm{x}^{2} \mathrm{e}$ as alturas HA e HD foram transformadas em $\sqrt{ } \mathrm{x}$.

\section{RESULTADOS E DISCUSSÃO}

A ocorrência de geada no experimento foi observada no final da estação de outono nos dias 16 e 17 de junho de 2008, momento em que os valores mínimos absolutos de temperatura do ar atingiram -2,1 e $0,5^{\circ} \mathrm{C}$ respectivamente. A diferença entre a temperatura medida no abrigo meteorológico $(1,5 \mathrm{~m})$ e a medida na relva varia de $3,3^{\circ} \mathrm{C}$ (SILVA \& SENTELHAS, 2001). Considerando tal diferença entre as temperaturas, é provável que a temperatura mínima absoluta possa ter atingido valores inferiores aos observados.

Os maiores danos ocasionados por geada nas plantas, de acordo com PEREIRA et al. (2001), são observados quando as geadas ocorrem no início do outono, período com atividade vegetativa existente. A ocorrência da geada já no final dessa estação pode ter contribuído na resistência das espécies estudadas. Segundo os autores citados, ao se aproximar do inverno, as plantas encontram-se em repouso hibernal, com pouca atividade vegetativa, o que afeta positivamente na resistência à geada. Em anos atípicos, ocorreram cinco dias de geada na primeira quinzena de julho, resultando em grandes danos em plantios da espécie Eucalyptus grandis no município de Santa Maria(SELLE \& VUADEN, 2007).

As espécies tiveram diferentes comportamentos face à ocorrência de geadas. Na análise de variância, observaram-se diferenças significativas entre as espécies e a interação sistema agroflorestal e espécie para a variável dano ocasionado por geada (Tabela 1). Tal resultado, evidencia a suscetibilidade das culturas às baixas temperaturas, a qual varia muito de acordo com a espécie (BISCARO, 2007).

As espécies angico-vermelho, bracatinga e eucalipto destacaram-se em relação à resistência a geadas, ou seja, elas não apresentaram danos visíveis à parte aérea, logo, tiveram 100\% de sobrevivência, caracterizando-se como espécies resistentes (Tabela 2). Por sua vez, o guapuruvu e a canafístula foram inferiores as demais espécies, as quais apresentaram danos visíveis (Tabela 2).

A canafístula é medianamente tolerante às baixas temperaturas (INOUE \& GALVÃO, 1986) e ao inverno gaúcho, resultado semelhante ao observado neste trabalho, no qual esta espécie demonstra-se tolerante (Tabela 2). Nas condições de temperatura estudadas, $100 \%$ das plantas sofreram danos, assim como verificado por EMBRAPA (1986), já que danos a essa espécie foram observados com temperatura mínima de $-1^{\circ} \mathrm{C}$. CARVALHO (2003) destacou que essa espécie suporta entre 15 e 40 geadas por ano, sendo a temperatura do mês mais frio de 13,8 a $23,7^{\circ} \mathrm{C}$. Apesar de que todas as plantas tenham tido danos visíveis, elas apresentaram 100\% de sobrevivência.

O guapuruvu foi a espécie mais susceptível à geada (Tabela 2), sendo 100\% das plantas danificadas. Entretanto, elas mostraram alta capacidade de rebrota (100\%) e, por sua vez, não apresentaram mortalidade de plantas, conforme a análise estatística. No entanto, visualmente, observou-se a morte de uma no SF. CARVALHO (2003) destacou que essa espécie não tolera baixas temperaturas, suportando entre duas e cinco geadas por ano e temperatura do mês mais frio de 14 a $22,1^{\circ} \mathrm{C}$.

Pode ser observado que as injúrias para a espécie canafístula foram frequentes no terço superior e para o guapuruvu a partir da parte mediana superior. Ambas as espécies tiveram 100\% da área foliar danificada e a severidade do dano no caule foi maior nas partes da planta em que predominavam tecidos vegetativos de crescimento recente. Esse resultado também foi observado por CARVALHO (1981) analisando a competição entre espécies florestais nativas em Irati - PR. 


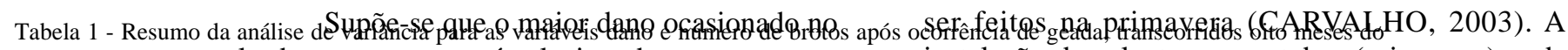

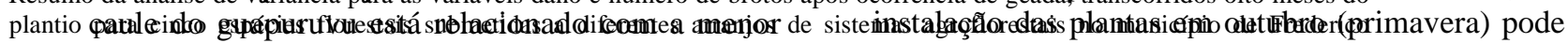

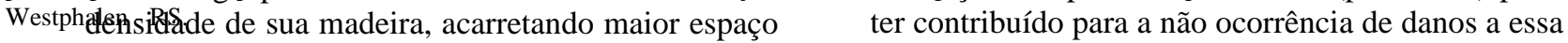
extracelular e, por consequêneia, maior quantidade de espécie.

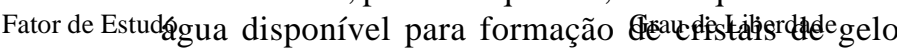

AWAäarado Médìos causados por geada em

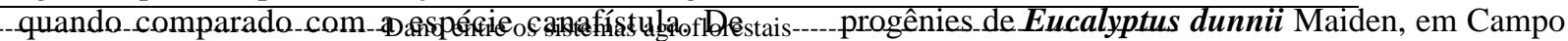
Sistema Agrofleferdo com SALISBURY \& ROSS1 (1994), o Espécie comportamento e tolerância de cada espécie com Sistema Agroftedexçẫo àsgéxaida baseia-se na formação de cristais de

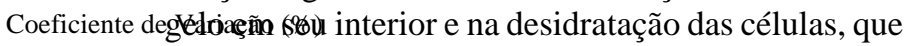

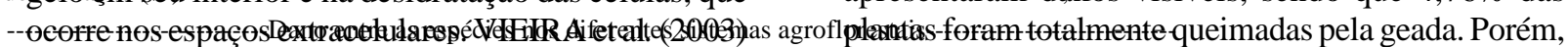

Angico-vermedæestacaram que a diferença da capacidade de tolerância Bracatinga à geada pode estar associada às diferençasłfisiológicas Canafístula e morfológicas existentes entre as espécieł. Relataram Eucalipto também que a queima de tecidos da planta pode estar Guapuruvu relacionada a fatores fisiológicos, antatômicos e do Tenente, PR,tatamp bém pelo sistema de notas, em sua avaliação um mêssanpén 550 corrência de geada, HIGA et al. (2000) obs,e885tam que todas as plantas apresentaram dạoms visíveis, sendo que 4,76\% das nove meses apó́\$3 687 gể da, 3,87\% das plantas não

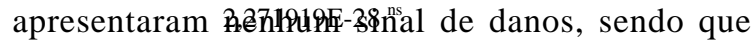

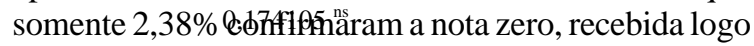
após a geada. ES3 dados obtidos 5 hespie triabalho. Apesar de serem

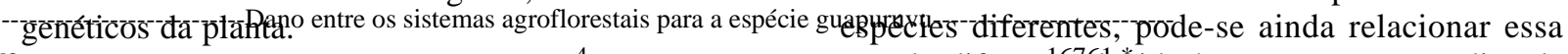
Sistema Faixa A bracatinga é uma espécie ${ }^{4}$ que não é, Sistema Linha generalizadamente, tolerante às gêadas. Em

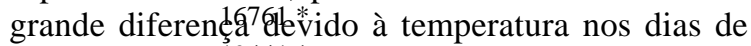
ocorrência de geâałs ${ }^{*}$ serem menores no experimento

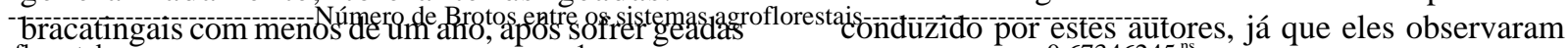
Sistema Agroflorestal Espécie parcialmente queimadas, inclusive plantas não Sistema Agroflorestal** Espécie que aftados adversos ao observado no Coeficiente de Variafâo (\%)
trabalio, no qual a espécie demonstra-se resistente.

No sul do Brasil, plantios realizados após março podem * Significativo a $5 \%$ de probabilidade de errg. por geadas severas no primeiro ano, os plantios devem temperatura de $-6,673646245^{\text {ns }}$ corrência da primeira geada. Temperaturats a abaixo ou próximas de $0^{\circ} \mathrm{C}$ (medidas em abrigo meteorológico) ocasionam danos em eucaliptos, resulutando desde a perda da área foliar até a morte das plantas (PALUDZYSZYN FILHO \& SANTOS, 2005), o que também não foi constatado neste trabalho. Os diferentes resultados podem ser

Ciência Rural, v.41, n.6, jun, 2011. 
Tabela 2 - Comparação de médias para as variáveis dano (notas atribuídas às plantas), diâmetro da copa (m) e resistência após ocorrência de geada, transcorridos oito meses do plantio para cinco espécies florestais submetidas a diferentes arranjos de sistemas agroflorestais no município de Frederico Westphalen - RS.

\begin{tabular}{|c|c|c|}
\hline \multirow{2}{*}{$\begin{array}{l}\text { Fator de Estudo } \\
\text { Espécie }\end{array}$} & \multicolumn{2}{|c|}{ 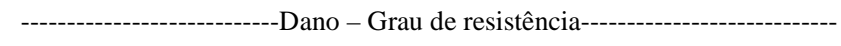 } \\
\hline & Sistema Agroflorestal Faixa & Sistema Agroflorestal Linha \\
\hline Angico-vermelho & $100 a-R^{1}$ & $100 \mathrm{a}-\mathrm{R}$ \\
\hline Bracatinga & $100 \mathrm{a}-\mathrm{R}$ & $100 \mathrm{a}-\mathrm{R}$ \\
\hline Canafístula & $16 \mathrm{~b}-\mathrm{T}$ & $16 \mathrm{~b}-\mathrm{T}$ \\
\hline Guapuruvu & $7,9 \mathrm{~d}-\mathrm{S}$ & 11,5 c - MT \\
\hline Eucalipto & $100 \mathrm{a}-\mathrm{R}$ & $100 \mathrm{a}-\mathrm{R}$ \\
\hline \multicolumn{3}{|l|}{ Sistema Agroflorestal* } \\
\hline Sistema Faixa & \multicolumn{2}{|c|}{$1,57 \mathrm{a}$} \\
\hline Sistema Linha & \multicolumn{2}{|c|}{1,37 a } \\
\hline Coeficiente de Variação (\%) & \multicolumn{2}{|c|}{50,85} \\
\hline Média & \multicolumn{2}{|c|}{1,47} \\
\hline Espécie & \multicolumn{2}{|c|}{-----------------------------Diâmetro da copa (m) ---------------------------- } \\
\hline Angico-vermelho & \multicolumn{2}{|c|}{$0,37 \mathrm{~b}$} \\
\hline Bracatinga & \multicolumn{2}{|c|}{$1,12 \mathrm{~b}$} \\
\hline Canafístula & \multicolumn{2}{|c|}{$1,08 \mathrm{~b}$} \\
\hline Guapuruvu & \multicolumn{2}{|c|}{$1,94 \mathrm{a}$} \\
\hline Eucalipto & \multicolumn{2}{|c|}{$1,73 \mathrm{a}$} \\
\hline Coeficiente de Variação (\%) & \multicolumn{2}{|c|}{50,85} \\
\hline Média & \multicolumn{2}{|c|}{1,47} \\
\hline
\end{tabular}

Médias seguidas por letras distintas na coluna diferem entre si pelo teste de Tukey a 5\% de probabilidade .

* Para diâmetro de copa, médias seguidas por letras distintas na coluna diferem entre si pelo teste de $\mathrm{F}$ a 5\% de probabilidade

${ }^{1}$ Em que: $\mathrm{R}=$ resistente, $\mathrm{T}=$ tolerante, $\mathrm{S}$ = sensível e $\mathrm{MT}=$ Moderadamente tolerante

explicados pela maior resistência às geadas de algumas plantas (HIGA, 1998). VIEIRA et al. (2003) destacaram que a diferença da capacidade de tolerância à geada pode estar associada às diferenças fisiológicas e morfológicas existentes entre as espécies e até dentro de uma mesma espécie, podendo também a queima de tecidos da planta estar relacionada a fatores fisiológicos, anatômicos e genéticos da planta.

Quando avaliado o efeito do dano e resistência, o guapuruvu foi a única espécie que teve comportamento diferente entre os diferentes arranjos de sistema agroflorestal conforme análise estatística (Tabela 1), demonstrando ser sensível no SF e moderadamente tolerante no sistema linha (SL) (Tabela 2). Tal comportamento está diretamente relacionado com a densidade de plantio e tamanho da copa. Quando analisados os efeitos simples de dano dentro do sistema para a espécie guapuruvu, a análise estatística aponta menor dano e maior grau de resistência no SL (Tabela 2). Nesse caso, pode-se relacionar a maior densidade de plantas no SL quando comparado ao SF. Na linha de plantio do SL, observou-se um dossel fechado, formado pela copa das plantas, fato que pode estar diretamente ligado à mudança de condições microclimáticas, beneficiando de maneira positiva a espécie. Espera-se que o dossel tenha proporcionado menores perdas noturnas de radiação, como demonstrado nos trabalhos conduzidos por MARIN et al. (2003) e PILAU et al. (2007), interferindo nos valores de temperatura mínima, ou seja, interferindo no resfriamento noturno, resultando no maior acúmulo de calor e menor dano na planta. Tal resultado também é evidenciado por CARAMORI et al. (2004), pois esses autores relataram que a redução das perdas radiativas durante a noite minimiza danos ocasionados por geada nas plantas.

De acordo com análise estatística, o diâmetro de copa não apresentou interação significativa entre os sistemas agroflorestais. Porém, entre as espécies, o guapuruvu e eucalipto apresentaram diâmetros superiores às demais espécies (Tabela 2). Mesmo não tendo diferenças de diâmetro de copa entre os sistemas agroflorestais, a formação de um dossel fechado na linha de plantio foi observada somente com a espécie guapuruvu e eucalipto no SL, no qual as plantas estão dispostas a cada $1,5 \mathrm{~m}$ na linha de plantio. No sistema faixa (SF), devido à distância de 3m entre plantas, não foi possível a formação do dossel, pois os diâmetros da copa das árvores ainda não 
possuíam dimensões suficientes para que as copas se entrelaçassem uma à outra.

Mesmo o dano sendo menor no guapuruvu no SL, o número de brotos não foi influenciado pelo sistema, assim como para a canafístula (Tabela 1). O guapuruvu brota em qualquer altura do tronco, principalmente quando afetada por geada, resultado observado visualmente no campo. Diferentemente da canafístula, o guapuruvu é uma espécie que possui crescimento monopodial, contudo, é necessária a poda e condução de brotos nas plantas afetadas por geadas (CARVALHO, 2003) para o desenvolvimento de um único caule.

As espécies guapuruvu e canafístula acarretaram perdas no crescimento em altura com a ocorrência da geada. De acordo com a análise estatística, as alturas HA e HD foram significativas para essas espécies, sendo os valores médios de HA e de HD 0,95 e $0,88 m$ para a canafístula e para o guapuruvu $1,21 \mathrm{~m}$ e $0,78 \mathrm{~m}$, respectivamente. $\mathrm{O}$ crescimento das plantas é retomado nas partes do caule em que não houve dano por geada. A recuperação do crescimento e desenvolvimento de cada espécie vai depender de sua capacidade de resiliência, o quanto e como o dano provocado pela geada influenciará o crescimento e desenvolvimento das plantas dependerá de estudos futuros.

\section{CONCLUSÕES}

Os diferentes arranjos de sistema agroflorestal, em função do espaçamento entre as plantas e formação de dossel, afetam a resistência da espécie guapuruvu (Schizolobium parahyba), sendo sensível no sistema agroflorestal faixa e pouco sensível no sistema linha.

As espécies angico-vermelho (Parapiptadenia rigida), bracatinga (Mimosa scabrella) e eucalipto (Eucalyptus urophylla $\mathbf{x}$ Eucalyptus grandis) mostram-se muito resistentes, enquanto que a canafístula (Peltophorum dubium) demonstra ser resistente.

\section{REFERÊNCIAS}

BISCARO, G.A. Meteorologia agrícola básica. Cassilândia: UNIGRAF, 2007. 86p.

CARAMORI, P.H. et al. Utilização de espécies intercalares no cafezal para proteção contra geadas: resultados e perspectivas. Agroecologia Hoje, Botucatu - SP, v.23, p.11-13, 2004.

CARVALHO, P.E.R. Competição entre espécies florestais nativas em Irati - PR, cinco anos após o plantio. Colombo - PR: Embrapa Florestas, 1981. 131p. (Boletim de Pesquisa Florestal, 2).

CARVALHO, P.E.R. Espécies arbóreas brasileiras. Brasília: Embrapa informação tecnológica; Colombo - Paraná: Embrapa Florestas, 2003. V.1, 1039p.
EMBRAPA. Empresa Brasileira de Pesquisa Agropecuária. Centro Nacional de Pesquisa de Florestas (Curitiba, PR). Zoneamento ecológico para plantios florestais no Estado do Paraná. Brasília: EMBRAPA-DDT, 1986. 89p. (EMBRAPA-CNPF. Documentos, 17).

HIGA, R.C.V. Avaliação e recuperação de Eucalyptus dunnii Maiden atingidos por geadas em Campo do Tenente, PR. 1998. 100f. Tese (Doutorado em Engenharia Florestal) Curso de Pós-graduação em Engenharia Florestal, Universidade Federal do Paraná, PR.

HIGA, R.C.V. et al. Resistência e resiliência a geadas em Eucalyptus dunnii Maiden plantados em Campo de Tenente. Boletim de Pesquisas Florestais, Colombo - PR, n.40, p.67-76, 2000.

INOUE, M.T.; GALVÃO, F. Desempenho assimilatório de Mimosa scabrella, Peltophorum dubium, Schinus terebinthifolius e Matayba elaeagnoides, em dependência da intensidade luminosa. Acta Forestalia Brasiliensis, Curitiba, v.1, n.1, p.89-98, 1986.

MALUF, J.R.T. Nova classificação climática do Estado do Rio Grande do Sul. Revista Brasileira de Agrometeorologia, Santa Maria, v.8, n.1, p.141-150, 2000.

MARIN, F.R et al. Solar radiation interception and its relation in different coffee canopy layers. Revista Brasileira de Agrometeorologia, Santa Maria, v.11, n.1, p.219-228, 2003.

OSPINA-ANTE, A. Agroforestería. Aportes conceptuales, metodológicos y prácticos para el estudio agroforestal. Santiago de Cali: ACASOC, 2006. 209p.

PALUDZYSZYN FILHO, E.; SANTOS, P.E.T. Considerações sobre o plantio de Eucalyptus dunnii, no estado do Paraná. Colombo: EMBRAPA, 2005. 7p. (Comunicado Técnico, 141).

PEREIRA, A.R. et al. Agrometeorologia: fundamentos e aplicações práticas. Guaiba, RS: Agropecuária Guaíba, 2001. 478p.

PILAU, F.G. et al. Radiation balance of an orange tree in orchard and its relation with global solar radiation and grass net radiation. Revista Brasileira de Agrometeorologia, Piracicaba, v.15, n.3, p.257-266, 2007. Disponível em: <http://www.sbagro.org.br/ rbagro/ojs/index.php/rbag ro/article/viewFile/66/17>. Acesso em: 12 dez. 2010.

SALISBURY, F.B.; ROSS, C.W. Plantphysiology. 4.ed. Belmont: Wadworth Publisher, 1994. 389p.

SAS LEARNING EDITION. Getting started with the SAS Learning Edition. Cary, 2002. 200p.

SELLE, G.L.; VUADEN, E. Comunicação: efeitos da geada sobre plantações de Eucalypus grandis. Caderno de pesquisa, série Biologia, Santa Cruz do Sul, v.20, n.1, p.36-45, 2007.

SILVA, J.G.; SENTELHAS, P.C. Diferença entre temperatura mínima do ar medida no abrigo e na relva e probabilidade de sua ocorrência em eventos de geadas no Estado de Santa Catarina. Revista Brasileira de Agrometeorologia, Santa Maria, v.9, n.1, p.9-15, 2001

VIEIRA, A.R.R. et al. Adaptação de espécies arbóreas nativas em um sistema agrossilvipastoril, submetidas a extremos climáticos de geada na região de Florianópolis. Revista Árvore, Viçosa-MG, v.27, n.5, p.627-634, 2003. Disponível em: <http://www.scielo.br/ scielo.php?script=sci arttext\&pid=S01007622003000500005\&ln $\mathrm{g}=\mathrm{p}$ t\& nrm=iso $>$. Acesso em: 20 jul. 2010. doi: 10.1590/S010067622003000500005 